Published as: Liu, X., Derudder, B. \& Gago Garcia, C. (2013) Exploring the coevolution of the geographies of air transport aviation and corporate networks.

Journal of Transport Geography, 30, 26-36.

\title{
Exploring the co-evolution of air transport aviation and corporate networks
}

Xingjian Liu, Ben Derudder, Cándida Gago García 


\title{
Exploring the co-evolution of air transport aviation and corporate networks
}

\begin{abstract}
In this paper we aim to contribute to the literature on the empirical parallels between urban hierarchies and the transport networks supporting and/or reflecting these hierarchies. We adopt a stochastic actor-based modeling framework to analyze the co-evolution of the world city hierarchy and global air passenger networks between 2000 and 2010/2011. The data are drawn from an inventory of the location strategies of globalized service firms across world cities and the International Civil Aviation Organization (ICAO). Major findings include (1) exogenous effects, such as the impact of economic development and regionality; (2) endogenous micro-level effects producing macro-level patterns, such as preferential attachment processes; and (3) the two-way impact of both networks. (i.e., cities that are well connected in the aviation network tend to attract more major offices of globalized service firms, while the co-presence of major offices of globalized service firms in cities in turn stimulates the development of aviation connections between them).
\end{abstract}

\section{Keywords}

Urban hierarchies, transportation network, intercity corporate network, stochastic actor-based modeling

\section{Highlights}

- Exploring empirical parallels between urban hierarchies and the transport networks supporting and/or reflecting these hierarchies;

- Dynamics for individual intercity networks are driven by both endogenous and exogenous network effects;

- Aviation and APS networks co-evolve over time, with significant two-way impacts. 


\section{Introduction}

Within transport geography, the geographical contours of transport systems are often explicitly set in the context of the wider urban system (e.g. Murayama, 1994; Malecki, 2002; Derudder and Witlox, 2008). One particular area of attention in this literature relates to the ways in which the evolution of transport geographies shapes/is shaped by the urban system in which these geographies are embedded (e.g., O'Connor, 2003; O'Connor and Fuellhart, 2012; Tranos, 2012). When narrowing the research context down to the global scale, for instance, there have been analyses of the development of rail systems (e.g., Niedzielski and Malecki, 2012), Internet and telecommunication networks (e.g., Malecki and Wei, 2009), and air transport networks (e.g. O'Connor, 2003) in the context of the 'world city' hierarchy.

The methodological tools adopted in this literature vary widely, and have resulted in different levels of analytical detail. Malecki (2002), for instance, restricts his analysis to a general sketch of the related geographies of Internet backbone networks and world cities, while O'Connor (2003) analyzes the shifting concentration of air transport connectivity across the world city hierarchy (see also Derudder and Witlox, 2009). Taylor et al. (2007), in turn, use regression analysis to reveal overall parallels and differences between the world city hierarchy and global air transport geographies, while Tranos (2012) recently proposed a more refined framework for assessing parallels between urban systems and transport networks: a regression analysis incorporating lagged explanatory variables allows him to disentangle the coevolution of cities' hierarchical position and their involvement in Internet backbone networks in more detail. In particular, his framework allows evaluating whether urban-economic development is either driving or driven by the development of such infrastructures (see also Neal, 2011).

One element that has been lacking within the research dealing with the co-evolution of transport networks and the world city hierarchy, is a detailed appraisal of the underlying network formation processes: cities' centralities in the global urban hierarchy and the transport networks supporting and/or reflecting this hierarchy (however measured) are operationalized as homogenous macro-level variables, without consideration of the many different micro-level processes that may or may not feed the overall macro-level pattern. As a consequence, exactly how world cities and transport networks 'link up' over time remains unclear, as the focus tends to be firmly on macro-level parallels. In this paper, we aim to show that this literature may benefit from a more detailed consideration of the unfolding micro-level linkages between cities and transport systems.

To this end, this paper adopts a stochastic actor-based modeling framework to present a more comprehensive analysis of the co-evolution of global air passenger networks and the world city hierarchy. In particular, the methodological framework presented here allows linking comprehensive network-generation processes at the micro scale with the observed network parallels at the macro scale. The data used in our analysis are drawn from the International Civil Aviation Organization (ICAO) and the Globalization and World Cities (GaWC, http://www.lboro.ac.uk/gawc) research 
network, respectively. The ICAO data detail the number of scheduled flights in a given time period between airports, while the GaWC data describe the location strategies of advanced producer service (APS) firms across world cities for different points in time. After transforming the ICAO and GaWC databases so that consistent datasets of inter-city flows are established for 2000 and 2010/2011, we link the shifts that have occurred in the APS-generated urban network with shifting geographies of global air transport networks. Our key purpose is thereby to trace the global co-evolutions in the urban and transport network back to a mix of exogenous (e.g., external impacts such as economic development and geographical location) and endogenous processes (e.g., the emergence of micro-level network-formation processes). Although our empirical focus is centered on world cities and air transport, the methodology outlined here can also be used at different scales, for different transport modes, and for different operationalizations of urban standing.

The remainder of this paper is organized as follows. In the next sections, we introduce our modeling framework and data sources, respectively. We then formally specify our model and provide an overview of the results, after which the paper is concluded with an overview of key implications and a discussion of some avenues for further research.

\section{Stochastic actor-based modeling}

Stochastic actor-based models assume that actors making rational decisions on the forging of connections determine network changes, i.e. actors maximize a utility/objective function of network patterns (Snijders et al., 2010) ${ }^{1}$. In this case, this implies that cities are treated as 'actors' that make 'rational' decisions regarding their connections with other cities in the aviation network as well as hosting globalized APS firms ${ }^{2}$. The objective functions in stochastic actor-based models represent the local networking mechanisms that are linked with global network patterns (Snijders et al., 2010).

Similar to other generative models, stochastic actor-based models simulate network dynamics based on pre-defined model specifications and aim to generate simulated networks that maximally replicate the observed network (Warren, 2010). Network simulations are built upon utility-maximizing actors, and the objective functions are defined as the combinations of endogenous and/or exogenous network effects (Snijders et al. 2010). When a reasonable model specification is identified, the statistical significance of individual network effects can be directly tested (Snijders et al., 2010). Interestingly for our purposes, the modeling of the joint-dynamics of multiple networks can also include the effects of 'exogenous networks', i.e. a second

\footnotetext{
${ }^{1}$ Detailed descriptions about stochastic actor-based modeling can be found in Snijders et al. (2010) and Ripley et al. (2012). Utility and objective functions are used interchangeably in this paper.

${ }^{2}$ For most intercity network analyses, cities are treated as units of analyses. That is, the pairwise relationship between any two cities is used as a surrogate measurement for all interactions between individuals, firms, organizations, and institutions located within these cities. On the one hand, our treatment of cities as aggregated units of long-range interactions is thus similar to a one-mode network (e.g., the aviation network). On the other hand, our model explicitly acknowledges the importance of firms as the actual agents of intercity connectivity (e.g., firms in the intercity corporate network).
} 
network that shares nodes with the focal network, and thereby may influence the evolution of the focal network. For instance, individual cities' positions in the world city hierarchy can be treated as exogenous effects when our focus is on modeling dynamics in aviation networks (and vice versa).

During a single simulation run, a randomly selected actor $i$ changes one of its linkages, and the probability of this linkage change conditions on the objective function of potential network changes:

$$
p_{i}(\beta, X)=\frac{\exp \left(f_{i}(\beta, X)\right)}{\sum \exp \left(f_{i}\left(\beta, X^{\prime}\right)\right)}
$$

Where $X$ and $X^{\prime}$ represent networks that are generated by the focal connection change and other permissible changes by actor $i$, respectively; exp represents the exponential link function; $p_{i}(\beta, X)$ refers to the likelihood for the network to evolve into $X$ by next run; $f_{i}(\beta, X)$ represents the actor i's objective function; and $\beta$ are parameters for the objective function. Note that stochastic actor-based models require binary networks as inputs, so that in the case of ratio, interval or ordinal measures, researchers need to decide on a dichotomization procedure (Ripley et al., 2012)

The objective function forms the core of stochastic actor-based models, implemented as a series of network effects (Snijders et al., 2010):

$$
f_{i}(\beta, X)=\sum_{k} \beta_{k} s_{k i}(X)
$$

The network effects $s_{k i}(X)$ summarize micro-level endogenous network topologies and/or exogenous attributes (e.g., nodal attributes and link properties) that are conjectured to be responsible for actors' networking behaviors. The effect parameters $\beta_{k}$ capture the size, direction, and significance of corresponding network effects: a positive parameter indicates that the network evolves towards a position with a higher value for the corresponding effect, while a negative parameter implies that the network is prone to evolve towards a position status with a lower value for the corresponding effect. For instance, the so-called 4-cycle effect among APS firms' locational strategies consists of two cities ( $A 1$ and $A 2$ ) and two firms (B1 and B2), whereby both firms (B1 and $B 2$ ) have major offices in both cities ( $A 1$ and $A 2)$. $A$ positive and significant 4-cycle effect implies that individual firms have tended to follow other firms' locational strategies between $t 1$ and $t 2(A 1 \rightarrow B 1, A 1 \rightarrow B 2$ and $A 1 \rightarrow B 2$ jointly imply $A 2 \rightarrow B 2$ ); a negative and significant 4-cycle effect indicates that individual firms have tended to avoid copying other firms' locational strategies between $t 1$ and $t 2$ (for example, $A 1 \rightarrow B 1, A 1 \rightarrow B 2$ and $A 1 \rightarrow B 2$ jointly imply not $A 2 \rightarrow B 2)$; and a non-significant 4-cycle effect indicates that neither patterns is clearly visible between $\mathrm{t} 1$ and $\mathrm{t} 2$.

Our aim here is to include theoretically sound and empirically feasible/available network effects for our models, and the selected network effects will be elaborated for both networks after discussing our data. 


\section{Data collection}

We model the co-evolution of aviation networks and the presence of globalized APS firms' in world cities based on abridged descriptions of both networks in 2000 (t1) and 2010 (t2).

The rationale behind the GaWC approach towards mapping the world city hierarchy is that globalized APS firms serve as key network agents among world cities (Sassen, 2001; Taylor, 2004). As a consequence, in the GaWC approach the empirical focus is on mapping the evolving presence of globalized APS firms' in world cities. Here we use information from the GaWC datasets for 2000 and $2010^{3}$. The original GaWC datasets characterize the geographic distribution of 100 firms in 315 cities for 2000 and 175 firms in 526 cities for 2010, detailing the relative importance of individual branches within firms' office network through a 6-point ratio scale ranging from 0 (no presence) to 5 (global headquarters). However, for reasons of consistency and computational ease, our analysis is restricted to (1) the 57 firms that have remained leading APS providers during the period 2000-2010; (2) major offices in the office networks, revealing the command and control structures of globalized APS firms (i.e. global and regional headquarters that score 4 or 5 in the GaWC data); and (3) the 91 cities that hosted at least one major office of the 57 firms in 2000 or $2010^{4}$.

Two two-mode adjacency matrices are the result of this data transformation. These binary two-mode networks capture the geographic distribution of 57 globalized APS firms in 91 cities in 2000 and 2010 (Table 1), with a value of 1 and 0 indicating the presence and absence of a major branch, respectively. Unlike more conventional one-mode networks that feature connections between actors of the same type (such as airline networks), a two-mode network represents the relationships between two disjoint sets of actors (Liu and Derudder, 2012). In our case, the two-mode intercity corporate network characterizes firms' presence in cities: the Outdegree connectivity in this intercity corporate network thus gauges the number of firms in individual cities, while the Indegree connectivity counts the number of cities in which individual firms have presence (Table 2a).

In general, the APS firm network expanded between 2000 and 2010: there are 232 major offices in 2000, and 333 in 2010 (Table 1). However, this overall rise obscures broader changes, as only 93 major offices remained in place and 139 and 240 major offices were closed/downgraded or opened/upgraded, respectively (for more details on change in the world city hierarchy, see Derudder et al., 2010). However, these changes have not implied a major overhaul in the Outdegree ranking, as a lot of changes in either direction are concentrated in the same set of cities, with London, New York and Hong Kong leading in Outdegree (i.e. hosting the most major offices of globalized APS firms).

\footnotetext{
${ }^{3}$ Detailed descriptions about the GaWC datasets in 2000 and 2010 can be found in Taylor (2001) and Taylor et al. (2013), respectively.

${ }^{4}$ Two cities (Palo Alto and Utrecht) that host major APS offices but do not have a major airport are added into neighboring major metropolis (San Francisco and Amsterdam, respectively).
} 


\section{[TABLE 1 ABOUT HERE]}

Our second dataset describes the evolving geographies of inter-city aviation networks. The initial data represent a more conventional one-mode network, wherein nodes represent the 91 selected cities, and linkages represent the total number of direct flights between these cities (as given in ICAO data for 2000 and 2011). To derive a meaningful binary dataset that reflects the relevance of individual connections as succinctly as possible, we adopted the following truncation procedure: the importance of city A in city B's aviation network is calculated as the ratio of flights between $A$ and $B$ over $B$ 's total flights. If flights are distributed randomly between cities, any city $A$ should account for approximately $1.1 \%(1 / 90)$ of city B's connections. A connection is regarded as significant and set to 1 if its importance is greater than $1.1 \%$, and 0 otherwise. For example, there are 17 flights monthly connecting Abidjan and Amsterdam for 2000. These 17 flights are deemed significant for Abidjan (accounting for 9.7\% of Abidjan's total number of flights), but not significant for Amsterdam (accounting for $0.2 \%$ of Amsterdam's total number flights). Meanwhile, the 1364 flights between New York (4.8\% of the total 27987 flights) and Los Angeles (9.3\% of the total 14631 flights) are important for both cities.

The end product of this data transformation is two asymmetric 91-by-91 binary matrices summarizing the relative importance of individual inter-city aviation connections in 2000 and 2011 (for other procedures to reveal nodes' significant linkages in air transport networks, see Van Nuffel et al. 2009 and Fuellhart and O'Connor 2012). A directional linkage from city A to city B reflects that the connection between $A$ and $B$ is significant for $A$. The Outdegree connectivity of a city therefore simply reflects how many cities the focal city has significant linkages to. Similarly, Indegree connectivity summarizes from how many cities the focal city receives significant linkages (Table $2 b$ ).

\section{[TABLE 2 ABOUT HERE]}

The number of significant air transport linkages rose from 1595 to 1698 between 2000 and 2011. During this study period, 1403 significant linkages remained unchanged, while 192 and 295 linkages were eliminated/downgraded or developed/upgraded, respectively. Overall, this points to stability, if not inertia in air transport networks (see Fuellhart and O'Connor, 2012). London, New York, Paris, Frankfurt, Amsterdam, Los Angeles boast the largest Indegree values in our transformed network, and are constantly ranked as the most popular cities in both years. Frankfurt, Istanbul, and London, in turn, had the most significant outgoing linkages in 2000, with Dubai rapidly rising to the top in this Outdegree ranking by 2011 (see Vespermann et al., 2008). Overall, there is less inequality amongst cities' connectivity in the aviation network than in the APS-generated network.

In addition to the data on the unfolding APS and airline networks between 2000 and 2010/2011, city-related data are also collected as exogenous variables: gross domestic product $(G D P)$ and population size $(P O P)$ for 2010, as well as regionality 
through three dummy variables (PAC, EUR and NAM), indicating cities' affiliations among the world's three most urbanized regions: Pacific Asia, Europe, and North America.

Although we believe that the data used here are amongst the best available, there are obviously some data issues as well. First, there is the extreme simplification of the airline and APS data because of the binary data requirement of the modeling framework. In the case of the GaWC data, however, it is worthwhile to note that our focus on global and regional headquarters actually tends to iron out some of the subjectivity in the GaWC data gathering (Liu and Taylor, 2011). In addition, above all this simplification serves our goal of acquiring a better understanding of how transport networks and APS networks link up over time. Second, t2 (2000 versus 2011 ) is slightly different for both networks. Third, rather than including evolution in population size or GDP, these variables are treated static background dummy variables for a single point in time (2010 for most cities). In addition, no firm-specific exogenous effects are included in the model, as the relevant data is extremely hard to assemble. And finally, the ICAO data features the individual legs of trips rather than the complete origin-destination routes, which is a widely acknowledged caveat in analyses of urban systems based on airline data (Derudder and Witlox, 2008).

Now that we have introduced the potential of stochastic actor-based modeling and the data used to map the co-evolution of both networks, we are in a position to provide a formal model specification. Effectively, this implies elaborating on the potential endogenous network structures at play in the unfolding of the networks between $\mathrm{t} 1$ and $\mathrm{t} 2$.

\section{Model specification}

\section{Modeling the evolution of the world city network}

The APS firms' networks part of our model involves four effects for both endogenous and exogenous networking mechanisms (Table 3$)^{5}$.

A positive Density parameter implies that individual firms deploy many major offices (e.g., a global or regional headquarter in each major world region), whereas a negative estimate corresponds to the case that most firms have a limited number of headquarters (e.g., only a global headquarter). The Outdegree activity and Indegree popularity effects indicate preferential attachment processes (Snijders et al., 2010), which give rise to the global hierarchies of cities and firms (Neal, 2008). More specifically, the Outdegree (city) activity effect captures the trend that cities with many offices at $\mathrm{t} 1$ tend to accumulate more offices over time. Likewise, a positive Indegree popularity (firm) effect indicates that firms with many branches are prone to pursue expansive locational strategies. The so-called 4-cycle effect was discussed earlier as an example of the modeling framework: a positive effect indicates that

\footnotetext{
${ }^{5}$ Our current analysis controls for a set of basic endogenous network effects (Snijders et al., 2010; Ma and Timberlake 2012), which are fundamental to the formation of most networks. Meanwhile, other complex endogenous effects can be implemented in RSiena to test more specific hypotheses.
} 
individual firms that are co-located in a city at $\mathrm{t} 1$ have further mimicked each other's location strategies by t2. Only four city-related Ego exogenous effects are included ${ }^{6}$.

[TABLE 3 ABOUT HERE]

Modeling the evolution of the aviation network

The aviation network part of our model hypothesizes the network generation as a function of six endogenous (network-based) effects and twelve exogenous (attribute-based) covariates (Table 4).

Similar to intercepts in conventional regression analyses, the Density effect benchmarks the overall tendency for cities to make aviation linkages. A positive Indegree popularity/Outdegree activity effect implies that cities receive/send more aviation linkages are more likely to gain additional connections, with negative effects suggesting the opposite trends.

The model also includes three effects that account for the interdependence among aviation connections: the reciprocity effect measures the tendency towards mutuality in aviation connections. A positive reciprocity effect suggests that a flow between city $A$ and $B$ would become significant for both $A$ and $B$. Transitivity effects (triplets and 3-cycle) reflects the tendency of two cities $A$ and $B$ to become linked if both cities share a neighbor (city $C$ ) in the network. A positive triplets effect supports a local hierarchical mechanism $(C \rightarrow A$ and $C \rightarrow B$ jointly imply $A \rightarrow B)$, and a positive 3cycle effect indicates a triadic closure process and counters local hierarchical ordering $(C \rightarrow A$ and $A \rightarrow B$ jointly imply $B \rightarrow C$ ).

We include three exogenous effects for each of the four covariates (GDP, population, Pacific-Asian cities, and European cities) ${ }^{7}$ : the effect of sender's covariates on linkage change (the ego effect); the effect of receiver's covariates (the alter effect); and the effect of both sender and receiver's covariates (the similar effect). For example, a positive Population ego effect and a positive Population alter effect suggest that more populous cities would send and receive more aviation linkages, respectively; moreover, a positive similar Population effect implies that cities tend to link with other cities of similar population sizes; negative parameters would suggest that patterns are unfolding the opposite way.

[TABLE 4 ABOUT HERE]

\section{Co-evolution of the two networks}

The final part of our modeling exercise lies in its potential to look at interaction effects between both previously specified networks: four interaction effects

\footnotetext{
6-7 Regional effects for North American are not statistically significant and thus excluded.
} 
measures the interdependence among cities' positions in different networks (Table 5, see also Tranos, 2012). A positive Aviation outdegree to GaWC activity effect supports the trends for cities with more air transport connections to host more globalized APS firms. Furthermore, a positive Aviation agreement to GaWC effect suggests that two cities significantly connected by air transport at $\mathrm{t} 1$ result in them co-hosting more major offices of firms at t2. The GaWC outdegree to Aviation activity effect tests whether the number of firms a city host at $\mathrm{t} 1$ is correlated with its connectivity in the aviation network at $\mathrm{t} 2$, while the GaWC agreement to Aviation effect captures the tendency for two cities co-hosting major offices of the same APS firms at $\mathrm{t} 1$ to be significantly connected in the aviation network at $\mathrm{t} 2$.

\section{[TABLE 5 ABOUT HERE]}

To sum up, by modeling endogenous and exogenous network mechanisms and accounting for interactions between networks, the co-evolution of air transport and globalized APS networks is directly tested with our stochastic actor-based model. Models are implemented with the RSiena package (Ripley et al. 2012; Conaldi et al. 2012). The goodness-of-fit measurements for our SABMs can be found in Appendix 1.

\section{Results}

Macro-level parallels

By way of introduction to the modeling results, we begin with a straightforward macro-level description of the (evolving) parallels between the APS-produced world city hierarchy and air transport networks. Table 6 presents a correlation matrix based on Spearman's rank-order correlations for cities' position in the different connectivity rankings for both $\mathrm{t} 1$ and $\mathrm{t} 2$. Overall, the level of change seems limited, as the correlations between Aviation Indegree and Aviation Outdegree on the one hand and GaWC Outdegree on the other hand remains largely stable between 2000 and 2010. In line with previous research, these associations are statistically significant, but far-from-perfect (see Taylor et al., 2007).

However, it is unclear whether this is due to an overall stability in the relation, or rather a near-zero-sum outcome of different tendencies in the linking processes between both networks. Or, put differently: such a correlation analysis only provides a general appraisal of the evolving association between cities' positions within different networks, while our modeling results allow revealing how the connections between both networks have emerged or dissolved over time.

\section{[TABLE 6 ABOUT HERE]}

Table 7 presents an overview of the parameter estimates. In the event, forward model selection, Wald tests, and score-type tests are employed to exclude network effects that do not improve model fits (Snijders et al., 2010). The effect parameters capture the size, direction, and significance of individual network effects. The 
remainder of this section focuses on the modeling results and the linking processes these reveal.

\section{[TABLE 7 ABOUT HERE]}

\section{Evolution of the intercity corporate network}

In addition to the endogenous hierarchical processes (Density, Outdegree activity and Indegree popularity), exogenous socio-economic status (GDP and population), and exogenous geographic disparities (Pacific Asian and European effects), the dynamics of the intercity corporate network also shows the interdependence among firms' locational strategies (4-Cycle),

The negative Density effect confirms that most APS firms have a limited number of headquarters. The positive Outdegree (city) activity effect suggests that newly entered firms prefer to locate in cities with many existing firms, i.e., a preferential attachment process. Preferential attachment processes in the intercity corporate network are often driven by agglomeration (or external) economies of scales, as the clustering of different producer services may benefit from labor-pooling, supporting infrastructures, and innovation/information spillovers (Neal, 2008; Drennan and Kelly, 2011). Similar to a "snowballing" scenario, a positive Indegree (firm) popularity effect indicates that firms with many branches are prone to continue their expansive locational strategies. The significant 4-cycle effect reflects interdependence among firms' locational strategies (Head et al., 1995; Taylor, 2004), while the clustering of globalized APS firms in rich cities (Pereira and Derudder, 2010) are confirmed by the positive GDP effect. As suggested by the negative Population effect, large populations do not offer advantage in attracting major offices. For example, many of the major cities in developing countries are also the world's most populous cities, whereas they host relatively few globalized APS firms. There is a negative effect for European cities and another positive effect for Pacific Asian cities, revealing the increasing importance of Pacific Asian cities found in other studies (Derudder et al., 2010).

\section{Evolution of the intercity aviation network}

The formation of the intercity aviation network for the period of 2000-2011 is mainly driven by endogenous hierarchical processes (transitive triplets, 3-Cycle, Outdegree activity, and Indegree popularity), as well as exogenous socio-economic and geographic effects (GDP, Pacific Asian and European effects).

As indicated by the negative Density effect, cities have on average not established new significant aviation connections. The positive Reciprocity effect indicates the tendency for mutuality in aviation connections, i.e., individual airline flows become important for cities on both ends. For example, a pair of reciprocal ties often signifies intensified social and economic linkages, and is often associated with convergence within urban systems (Ma and Timberlake, 2012). Indegree popularity effect reflects the Mathew Effects or preferential attachment process underlying the 
formation of aviation connections (Barabási and Albert, 1999; see also Vinciguerra et al., 2010), whereby cities with large number of aviation linkages are more likely to gain additional aviation connections. Conditioning on other effects (e.g., population and GDP), this preferential attachment process is mostly consistently with the huband-spoke strategies employed by individual airline carriers, which are designed to employ the (internal) economy of scale (Horner and O'Kelly, 2001; Campbell and O'Kelly, 2012). The negative Outdegree activity effect suggests that cities sending fewer linkages in 2000, i.e. 'peripheries' in the aviation network, are more likely to initiate new connections in 2011. The joint interpretation of Density, Outdegree activity, and Indegree popularity effects indicates that most new connections during our study period emerge between 'core' and 'peripheral' cities. The preferential attachment process gives rise to global hierarchies in the intercity aviation network, which are in turn reinforced by hierarchical processes at local level (the positive Transitive triplets and negative 3-Cycle effects).

We also find exogenous GDP and regionalization effects in the intercity aviation network. The positive GDP alter effects indicates that richer cities have on average acquired more aviation connections, and the positive GDP similarity effect indicates that cities tend to connect with cities with similar economic capacities. As suggested by the positive PAC same and EUR same effects, cities from the same region have better chances to be linked in the aviation network. The positive PAC ego and PAC alter effects indicate that Pacific Asian cities are more likely to gain aviation connections, and the negative EUR alter effects implies that European cities tend to receive less linkages. Although improving the overall model fit, population-related effects are not statistically significant.

\section{Interactions between intercity aviation and corporate networks}

A joint interpretation of the four interaction effects suggests that the aviation network have more influence on the APS-firm network than the other way around, as both aviation-originated interaction effects are statistically significant (Aiviation outdegree to GaWC activity and Aviation agreement to GaWC). The positive Aviation outdegree to GaWC effect suggests that globalized APS firms are prone to deploy major offices in cities with many aviation connections, while the positive Aviation agreement to GaWC indicates that firms are increasingly co-located in cities that are well-connected by air transport (see also Neal, 2011).

Both agreement effects (Aviation agreement to GaWC and GaWC agreement to Aviation) are positive, implying a reciprocal process in the evolution of both networks: well-connected cities in the aviation network are more likely to attract more APS firms, which in turn stimulate more aviation connections between them. In other words, the aviation network seems to facilitate the daily operation of APSfirms as the supporting infrastructure, while the co-location of multinational APS firms equally seems to be motivating new developments in aviation transport.

Finally, log odds ratios between likelihood of different network scenarios can be computed with the estimated parameters (Snijders, 2001; Snijders et al., 2010). For 
example, suppose city $A$ and $B$ are identical in terms of their attributes and positions in both networks, except that city $A$ has one more firm. All other effects being equal, the chance for city $A$, rather than city $B$, to gain an additional firm is $59 \%$ $(\exp (0.3686) /(\exp (0.3686)+1))^{8}$. Conditional on all other effects, the odds for a new aviation connection between two Pacific Asian cities against a new connection between a Pacific Asian city and any other city is 2.78 (exp(1.0227)), ceteris paribus, i.e., the binary probability of a Pacific Asian city to establish an aviation linkage with another Pacific Asian city is $74 \%$ (the PAC same effect in the aviation network). Calculations for more complex scenarios can be performed in a similar fashion, however with less straightforward interpretations.

\section{Discussion and conclusions}

In general terms, the purpose of this paper has been to present a methodological framework that allows revealing the network formation processes between cities' centrality in an urban system and the transport networks supporting and/or reflecting this system. Although our empirical focus was highly specific in that it dealt with world cities and global air transport networks (with the further complication of the former being specified as a two-mode network), this methodological framework can also be used at different scales, for different transport modes, and for different operationalizations of urban standing.

Given the specificity of our time intervals and data sources, as well as the impact of the different data transformations, we emphasize that our results are indicative rather than definitive. Nonetheless, our analytical framework allows identifying a number of patterns in the (co-)evolution of both networks, i.e.: (1) exogenous effects, such as the impact of GDP and regionality; (2) endogenous micro-level effects producing macro-level patterns within both networks, such as different preferential attachment processes; and (3) the way in which networks are impacting each other, such as the observation that cities that are well connected in the aviation network tend to attract more major offices of globalized APS firms, while the co-presence of major offices of globalized APS firms in turn stimulates the development of aviation connections between them. In addition, the way in which the model is specified allows plugging the estimated parameters into the objective function to calculate the log odds ratios between different network changes. Still, our analysis is concerned with association rather than causality between the two networks, as the latter requires data of longer periods and exclusion of confounding factors.

The limitations of our analysis also point to a number of avenues for further research. These could include sensitivity analyses through focusing on the impact of the dichotomization procedures employed here, as well as paying attention to the influence of the time interval. In addition, specifying and using other endogenous network effects may result in more comprehensive appraisals of how micro-level connections between urban hierarchies and transport systems co-evolve.

\footnotetext{
8 Note that this calculation only accounts for first-order impact, and does not consider impacts beyond second-order (e.g., aviation->corporate->aviation).
} 


\section{Tables}

Table 1. Descriptive network statistics

Table 2. Cities' connectivity rankings in the intercity aviation and corporate networks

Table 3. Network effects for intercity aviation network

Table 4. Network effects for intercity corporate network

Table 5. Joint dynamics of intercity aviation and corporate networks

Table 6. Spearman's rank-order correlations between cities' rankings

Table 7. Determinants of network formation 
Table 1 Descriptive network statistics

\begin{tabular}{|l|l|l|l|l|}
\hline Statistics & GaWC 2000 & GaWC 2010 & Aviation 2000 & Aviation 2011 \\
\hline Nodes & 91 cities and 59 firms & 91 cities & 0.207 \\
\hline Density & 0.043 & 0.062 & 0.195 & 18.659 \\
\hline Average degree & 2.549 & 3.659 & 17.527 & 1698 \\
\hline Existing ties & 232 & 333 & 1595 & \\
\hline Total potential ties & 5369 & 5369 & 8190 & \\
\hline Jaccard index & 0.197 & & 0.742 & \\
\hline $0 \rightarrow 0$ & 4897 & & 6300 & 295 \\
\hline $0 \rightarrow 1$ & 240 & & 192 & \\
\hline $1 \rightarrow 0$ & 139 & & 1403 & \\
\hline $1 \rightarrow 1$ & 93 & & & \\
\hline
\end{tabular}

The Jaccard Index measures the proportion of unchanged linkages during 2000 and 2010/2011, and networks with Jaccard Index greater are suitable to be analyzed by stochastic actor-based models (Snijders et al., 2010) 
Table 2. Cities' connectivity rankings in the intercity aviation and corporate networks

(a) Top-ranked cities in the intercity corporate network

\begin{tabular}{|l|l|l|l|l|}
\hline \multicolumn{3}{|l|}{ GaWC 2000 } & GaWC 2010 \\
\hline Rank & Cities & Outdegree & Cities & Outdegree \\
\hline 1 & New York & 38 & London & 39 \\
\hline 2 & London & 35 & New York & 31 \\
\hline 3 & Hong Kong & 13 & Singapore & 17 \\
\hline 4 & Chicago & 12 & Hong Kong & 16 \\
\hline 5 & Tokyo & 11 & Paris & 14 \\
\hline 6 & Frankfurt & 9 & Chicago & 11 \\
\hline 7 & Washington & 8 & Tokyo & 9 \\
\hline 8 & Los Angeles & 7 & Dubai & 9 \\
\hline 9 & Miami & 7 & Sydney & 8 \\
\hline 10 & Singapore & 7 & Washington & 6 \\
\hline
\end{tabular}

(b) Top-ranked cities in the intercity aviation network

\begin{tabular}{|l|l|l|l|l|l|l|l|l|}
\hline & \multicolumn{2}{|l|}{ Aviation 2000 } & \multicolumn{2}{l|}{ Aviation 2000 2011 } & \multicolumn{2}{l|}{ Aviation 2011 } \\
\hline Rank & Cities & Outdegree & Cities & Indegree & Cities & Outdegree & Cities & Indegree \\
\hline 1 & Frankfurt & 32 & London & 67 & Dubai & 37 & London & 66 \\
\hline 2 & Istanbul & 29 & New York & 60 & London & 33 & New York & 59 \\
\hline 3 & London & 27 & Paris & 52 & Amsterdam & 29 & Paris & 53 \\
\hline 4 & Zurich & 27 & Frankfurt & 50 & Paris & 29 & Frankfurt & 49 \\
\hline 5 & Paris & 26 & Amsterdam & 48 & Zurich & 29 & Amsterdam & 43 \\
\hline 6 & Amsterdam & 26 & Los Angeles & 42 & Athens & 27 & Los Angeles & 36 \\
\hline 7 & Brussels & 26 & Zurich & 39 & Brussels & 27 & Rome & 35 \\
\hline 8 & Moscow & 26 & Milan & 35 & Frankfurt & 27 & Barcelona & 34 \\
\hline 9 & Tel Aviv & 26 & Brussels & 34 & Istanbul & 27 & Madrid & 34 \\
\hline 10 & Vienna & 25 & Chicago & 31 & Munich & 27 & Milan & 34 \\
\hline
\end{tabular}


Table 3. Network effects for intercity corporate network

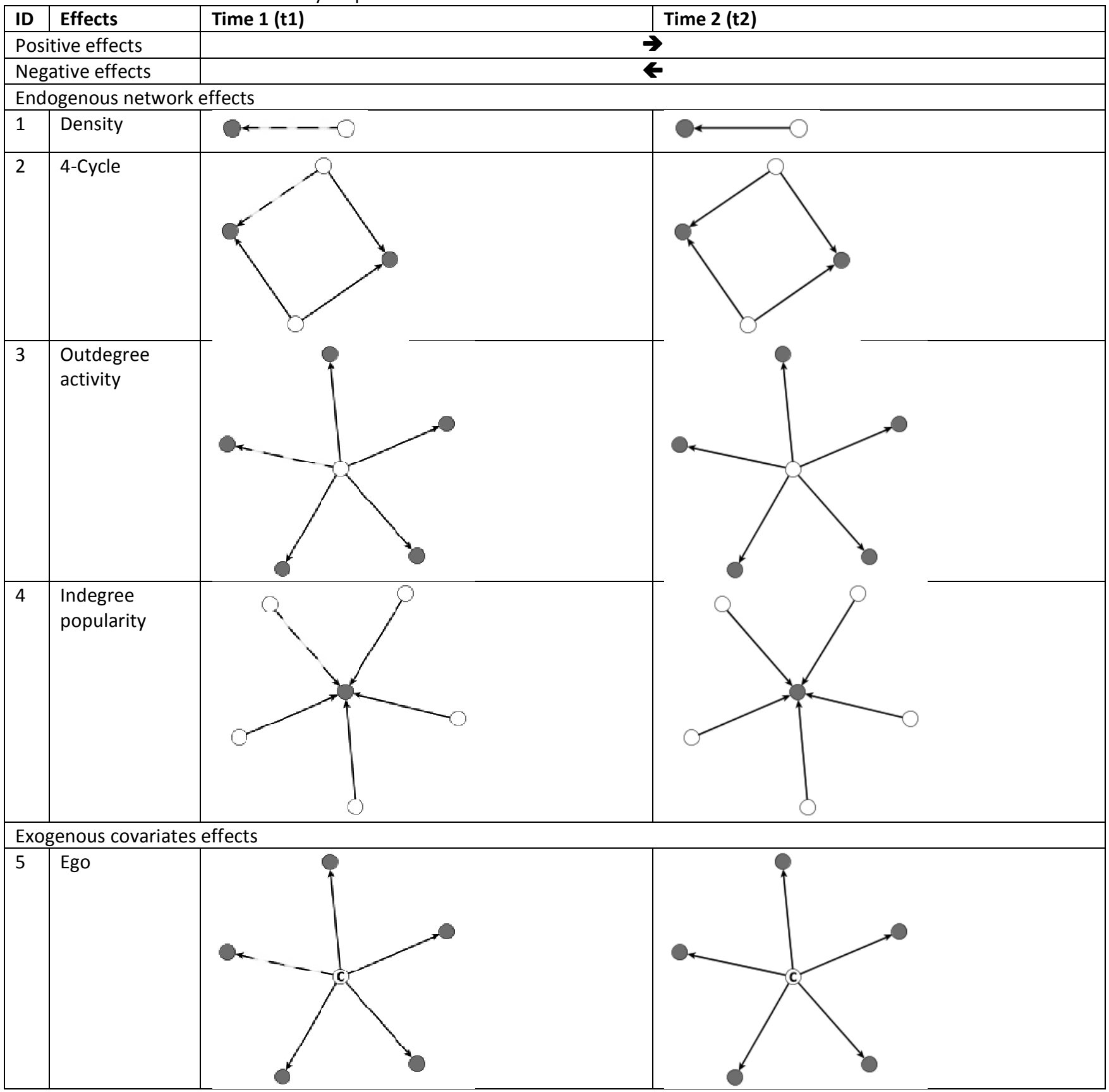

1. Cities and firms are represented as while and grey circles, respectively. A fable "c" marks cities with particular exogenous variables.

2. Dash and solid lines represent yet-to-exist and existing network ties at $\mathrm{t} 1$, respectively.

3. We only illustrate the cases for positive network effects. For the case of negative effects, local network structures are more likely to evolve from those in $\mathrm{t} 2$ to those in $\mathrm{t} 1$. 
Table 4. Network effects for intercity aviation network

\begin{tabular}{|c|c|c|c|}
\hline ID & Effects & Time 1 (t1) & Time 2 (t2) \\
\hline \multicolumn{4}{|c|}{ Endogenous network effects } \\
\hline 1 & Density & & \\
\hline 2 & Reciprocity & $\mathrm{C}--\rightarrow 0$ & \\
\hline 3 & Triplets & & \\
\hline 4 & 3-Cycle & & \\
\hline 5 & Outdegree activity & & \\
\hline 6 & Indegree popularity & & \\
\hline \multicolumn{4}{|c|}{ Exogenous covariates effects } \\
\hline 7 & Ego & $0 *---c$ & \\
\hline 8 & Alter & (c) $\leftarrow-$ & \\
\hline 9 & Similar & $(\mathrm{c} \div---\mathrm{c})$ & (c) \\
\hline
\end{tabular}

1. Cities are represented as circles, with the label "c" marking particular exogenous variables.

2. Dash and solid lines represent yet-to-exist and existing network ties at $t 1$, respectively.

3. We only illustrate the cases for positive network effects. For the case of negative effects, local network structures are more likely to evolve from those in $\mathrm{t} 2$ to those in $\mathrm{t} 1$. 
Table 5. Joint dynamics of intercity aviation and corporate networks

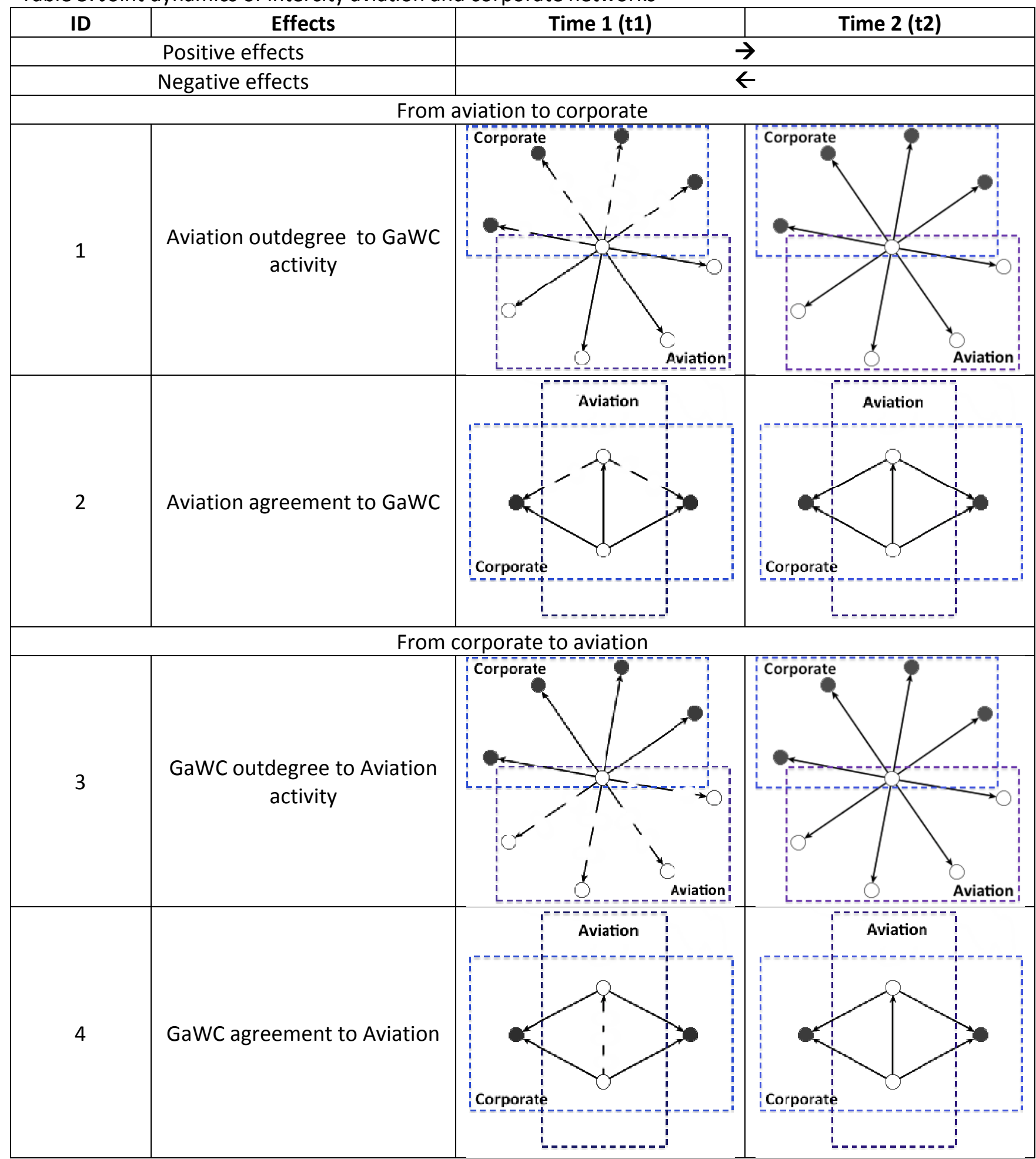

1. Cities and firms are represented as while and grey circles, respectively.

2. Network connections in both intercity aviation and coporate networks (two bounding rectangles in dash lines) are depicted. The overlapping area represents the interaction between two networks.

3. Dash and solid black lines represent yet-to-exist and existing network ties at $t 1$, respectively.

4. We only illustrate the cases for positive network effects. For the case of negative effects, local network structures are more likely to evolve from those in $\mathrm{t} 2$ to those in $\mathrm{t} 1$. 
Table 6 Spearman's rank-order correlations between cities' rankings

\begin{tabular}{|l|l|l|l|l|l|l|}
\hline & $\begin{array}{l}\text { Aviation 2000 } \\
\text { Outdegree }\end{array}$ & $\begin{array}{l}\text { Aviation 2000 } \\
\text { Indegree }\end{array}$ & $\begin{array}{l}\text { Aviation 2011 } \\
\text { Outdegree }\end{array}$ & $\begin{array}{l}\text { Aviation 2011 } \\
\text { Indegree }\end{array}$ & GaWC 2000 & GaWC 2010 \\
\hline $\begin{array}{l}\text { Aviation 2000 } \\
\text { Outdegree }\end{array}$ & & $0.754^{* *}$ & $0.846^{* *}$ & $0.740^{* *}$ & $0.375^{* *}$ & $0.390^{* *}$ \\
\hline $\begin{array}{l}\text { Aviation 2000 } \\
\text { Indegree }\end{array}$ & & & $0.769^{* *}$ & $0.939^{* *}$ & $0.555^{* *}$ & $0.464^{* *}$ \\
\hline $\begin{array}{l}\text { Aviation 2011 } \\
\text { Outdegree }\end{array}$ & & & $0.786^{* *}$ & $0.364^{* *}$ & $0.316^{* *}$ \\
\hline $\begin{array}{l}\text { Aviation 2011 } \\
\text { Indegree }\end{array}$ & & & & $0.454^{* *}$ & $0.453^{* *}$ \\
\hline GaWC 2000 & & & & & & \\
\hline GaWC 2010 & & & & & & $0.474^{* *}$ \\
\hline
\end{tabular}

** correlation significant at the 0.01 level 
Table 7 Determinants of network formation

\begin{tabular}{|c|c|c|}
\hline Network effects & \multicolumn{2}{|c|}{ Effects parameters } \\
\hline \multicolumn{3}{|l|}{ Intercity corporate network } \\
\hline \multicolumn{3}{|l|}{ Rate } \\
\hline Change rate & $23.5508^{*}$ & 3.3568 \\
\hline \multicolumn{3}{|l|}{ Endogenous network effects } \\
\hline Density & $-4.011 *$ & 0.2644 \\
\hline 4-Cycle & $-0.0162 *$ & 0.0097 \\
\hline Indegree popularity & $0.4542 *$ & 0.1082 \\
\hline Outdegree activity & $0.3686^{*}$ & 0.0511 \\
\hline \multicolumn{3}{|l|}{ Exogenous covariates effects } \\
\hline Population ego & $-0.8446 *$ & 0.3383 \\
\hline GDP ego & $0.8283^{*}$ & 0.3285 \\
\hline PAC ego & $0.2415^{*}$ & 0.116 \\
\hline EUR ego & $-0.3104 *$ & 0.1128 \\
\hline \multicolumn{3}{|l|}{ Intercity Aviation network } \\
\hline Rate & Estimate & S.D. \\
\hline Change rate & 9.5853* & 0.6574 \\
\hline \multicolumn{3}{|l|}{ Endogenous network effects } \\
\hline Density & $-2.4663^{*}$ & 0.553 \\
\hline Reciprocity & $2.3517^{*}$ & 0.1715 \\
\hline Transitive triplets & $0.1595^{*}$ & 0.0115 \\
\hline 3-Cycles & $-0.1443 *$ & 0.0191 \\
\hline Indegree Popularity & $0.1134 *$ & 0.0551 \\
\hline Outdegree Activity & $-0.3214^{*}$ & 0.0588 \\
\hline \multicolumn{3}{|l|}{ Exogenous covariates effects } \\
\hline Population alter & -0.3887 & 0.4167 \\
\hline Population ego & 0.5762 & 0.4345 \\
\hline Population similarity & 0.3184 & 0.3727 \\
\hline GDP alter & $1.5383^{*}$ & 0.5232 \\
\hline GDP ego & 1.0998 & 0.7068 \\
\hline GDP similarity & $0.9196 *$ & 0.4508 \\
\hline PAC alter & $1.1422 *$ & 0.2299 \\
\hline PAC ego & $1.0233 *$ & 0.2561 \\
\hline PAC same & $1.0227^{*}$ & 0.2292 \\
\hline EUR alter & $-0.2865 *$ & 0.1249 \\
\hline EUR ego & $0.5064 *$ & 0.1567 \\
\hline EUR same & $0.3068 *$ & 0.1159 \\
\hline \multicolumn{3}{|l|}{ Joint dynamics between networks } \\
\hline Aviation outdegree $\rightarrow$ GaWC activity & $0.2473 *$ & 0.1001 \\
\hline Aviation agreement $\rightarrow$ GaWC & $0.0944 *$ & 0.0513 \\
\hline GaWC outdegree $\rightarrow$ Aviation activity & -0.1891 & 0.1513 \\
\hline GaWC agreement $\rightarrow$ Aviation & $0.2201 *$ & 0.1229 \\
\hline
\end{tabular}

*Estimates are significant at 0.1 level 


\section{Appendix 1. Goodness-of-fit measurements for SABMs}

The validity of stochastic actor-based models can be assessed by comparing observed networks with networks that are simulated from the proposed model, i.e., measuring goodness-of-fit (Snijders et al., 2009; Conaldi et al., 2012). Smaller divergences between the observed and simulated networks suggest that the specified models (i.e., network effects) are more likely to capture the true underlying network mechanism, and vice versa. The properties of simulated networks are obtained by averaging over two thousand simulations based on SABMs specified in Table 7. The boxplots (Figure A1) represent degree distributions of the two thousand simulated networks, whereas the solid blue lines represent the observed degree distribution. For most degree values, the observed distribution falls within two standard deviations of the means of simulated distributions, implying a reasonably well goodness-of-fit. In addition, Table A1 summarises the differences between networks statistics of observed and simulated networks. All deviations between observed and simulated networks, excerpt for skewness, are less than $10 \%$.

Table A1. Goodness of fit measure based on 2000 simulations

\begin{tabular}{|l|l|l|l|}
\hline Aviation & Simulated & Observed & Difference (\%) \\
\hline Outdegree & & & \\
\hline Degree & 18.70 & 18.66 & -0.20 \\
\hline Standard deviation & 6.83 & 6.86 & 0.57 \\
\hline Skewness & -0.48 & -0.36 & -32.54 \\
\hline Indegree & & & \\
\hline Degree & 18.70 & 18.66 & -0.20 \\
\hline Standard deviation & 12.85 & 13.21 & 2.76 \\
\hline Skewness & 0.81 & 1.03 & 21.33 \\
\hline & & & \\
\hline GaWC & & & \\
\hline Cities & & & \\
\hline Degree & 3.70 & 3.66 & -1.24 \\
\hline Standard deviation & 6.38 & 6.44 & 0.90 \\
\hline Skewness & 4.41 & 4.32 & -2.18 \\
\hline Firms & & & \\
\hline Degree & 5.71 & 5.64 & -1.23 \\
\hline Standard deviation & 5.11 & 5.63 & 9.24 \\
\hline Skewness & 2.54 & 4.50 & 43.46 \\
\hline
\end{tabular}


Figure A1. Goodness of fit measured based on 2000 simulations

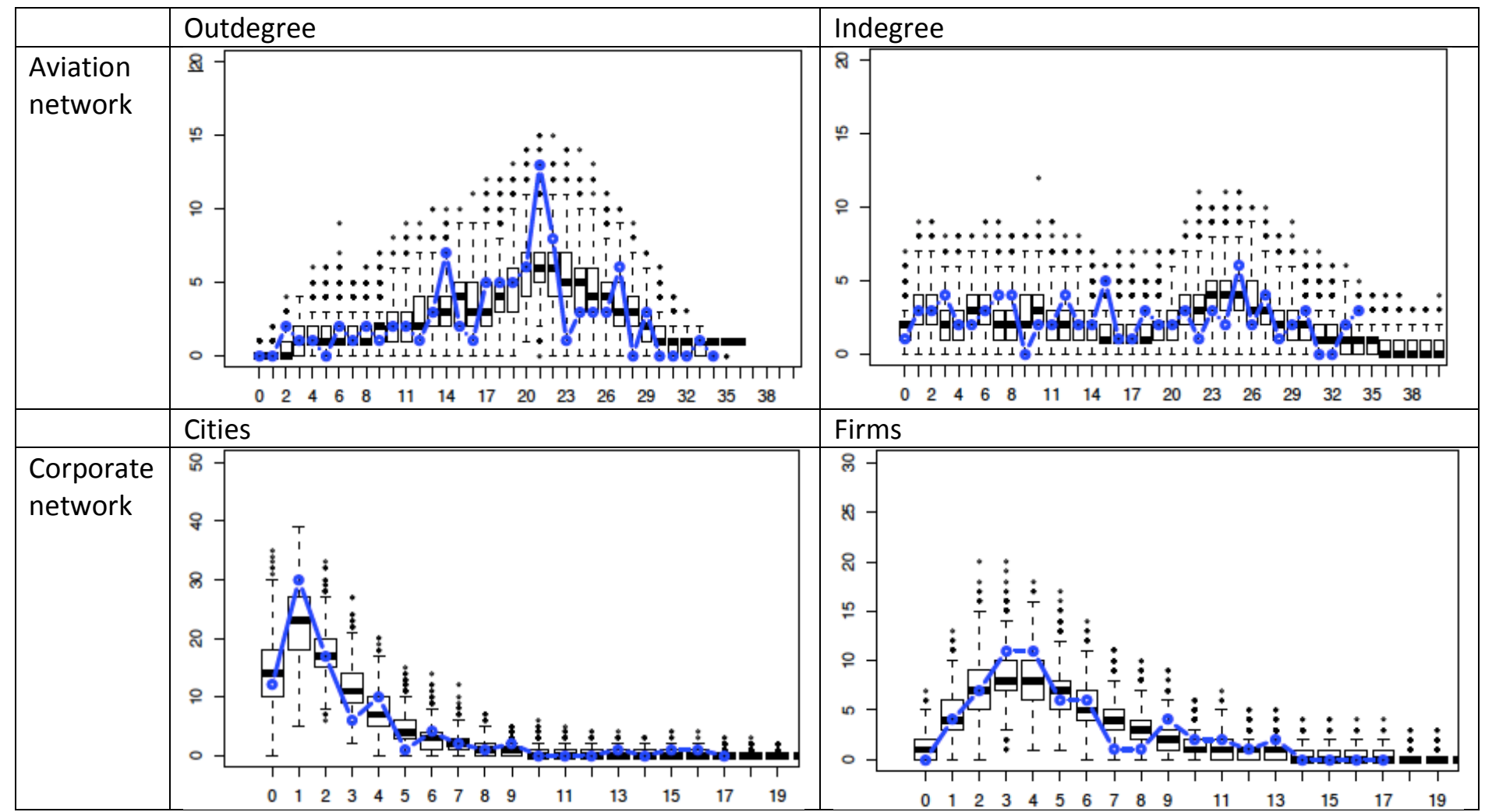

Degree distributions of (1) outgoing (outdegree) and incoming (indegree) ties in the aviation network; and (2) sending (cities) and receiving (firms) ties in the corporate network. The $\mathrm{X}$ - and $\mathrm{Y}$-axes represent degrees and number of cities/firms with corresponding degrees,

respectively. The box plots represent simulated degree distributions based on two thousand simulations, and the solid blue lines represent observed distributions. The empirically derived distributions may provide a reasonably well fit to the observed distribution, if the solid blue lines fall within boxplots for most degree values. 


\section{References}

Barabási, A., and Albert, R., 1999 Emergence of scaling in random networks. Science 286, 509.

Campbell, J., and O'Kelly, M. 2012. Twenty-five years of hub location research. Transportation Science 46(2), 153-169.

Conaldi, G., Lomi, A., Tonellato, M., 2012. Dynamic models of affiliation and the network structure of problem solving in an open source software project. Organizational Research Method, doi: 10.1177/1094428111430541

Derudder, B., and Witlox, F., 2008. Mapping world city networks through airline flows: context, relevance, and problems. Journal of Transport Geography 16(5), 305-312.

Derudder, B., and Witlox, F., 2009. The impact of progressive liberalization on the spatiality of airline networks: a measurement framework based on the assessment of hierarchical differentiation. Journal of Transport Geography 17, 276-284.

Derudder, B., Taylor, P., Ni, P., De Vos, A., Hoyler, M., Hanssens, H., Bassens, D., et al., 2010. Pathways of change: Shifting connectivities in the world city network, 2000-08. Urban Studies 47(9), 1861-1877.

Drennan, M., and Kelly, H. 2011. Measuring urban agglomeration economies with office rents. Journal of Economic Geography 11(3), 481-507.

Fuellhart, K., and O'Connor, K., 2012. Air services at Australian cities: Change and inertia 2005-2010. Geographical Research, doi: 10.1111/j.1745-5871.2012.00762.x

Head, K., Ries, J., Swenson, D., 1995. Agglomeration benefits and location choice: Evidence from Japanese manufacturing investments in the United States. Journal of International Economics 38, 223-247.

Horner, M., and O'Kelly, M., 2001. Embedding economies of scale concepts for hub network design. Journal of Transport Geography 9(4), 255-265.

Liu, X., and Taylor, P., 2011. A robustness assessment of GaWC global network connectivity ranking. Urban Geography 32, 1227-37.

Liu, X., and Derudder, B., 2012. Two-mode networks and the Interlocking World City Network Model: A reply to Neal. Geographical Analysis 44, 171-173.

Ma, X., and Timberlake, M. 2012. World city typologies and national city system deterritorialisation: USA, China and Japan. Urban Studies, doi: 10.1177/0042098012453859.

Malecki, E., 2002. The economic geography of the Internet's infrastructure. Economic Geography 78, 399-424. 
Malecki, E., and Wei, H., 2009. A wired world: The evolving geography of submarine cables and the shift to Asia. Annals of the Association of American Geographers 99, 360-382.

Murayama, Y., 1994. The impact of railways on accessibility in the Japanese urban system. Journal of Transport Geography 2, 87-100.

Neal, Z., 2008. The duality of world cities and firms: comparing networks, hierarchies, and inequalities in the global economy. Global Networks 8, 94-115.

Neal, Z., 2011. The causal relationship between employment and business networks in U.S. cities. Journal of Urban Affairs 33, 167-184

Niedzielski, M., and Malecki, E., 2012. Making tracks: Rail networks in world cities. Annals of the Association of American Geographers 102, 1409-1431.

O'Connor, K., 2003. Global air travel: toward concentration or dispersal? Journal of Transport Geography 11, 83-92.

O'Connor, K., and Fuellhart K., 2012. Cities and air services: the influence of the airline industry. Journal of Transport Geography 22, 46-52.

Ripley, M., Snijders, T.A.B., Preciado, P., 2012. Manual for RSiena. University of Oxford: Department of Statistics; Nuffield College.

Pereira, R., and Derudder, B., 2010. Determinants of dynamics in the world city network, 2000-2004. Urban Studies 47, 1949-1967.

Sassen, S., 2001. The global city. New York, London, Tokyo. New Jersey: Princeton Univ Press.

Snijders, T.A.B., 2001. The statistical evaluation of social network dynamics. In: Sobel, M.E., Becker, M.P., (Eds), Sociological Methodology. Boston and London: Basil Blackwell, pp. 361395.

Snijders, T.A.B., Van de Bunt, G.G., Steglich, C.E.G., 2010. Introduction to stochastic actorbased models for network dynamics. Social Networks 32, 44-60

Taylor, P., 2001. Specification of the world city network. Geographical Analysis 33(2), 181194.

Taylor, P., 2004. World city network: A global urban analysis. London: Routledge.

Taylor, P., Derudder, B., Witlox, F., 2007. Comparing airline passenger destination with global service connectivities: A worldwide empirical study of 214 cities. Urban Geography $28,232-248$. 
Taylor, P., Derudder, B., Hoyler, M., Ni, P., 2013. New regional geographies of the world as practised by leading advanced producer service firms in 2010. Transaction of the Institute of British Geographers, doi: 10.1111/j.1475-5661.2012.00545.x.

Tranos, E., 2012. The causal effect of the Internet infrastructure on the economic development of the European city-regions. Spatial Economic Analysis 73, 319-337.

Van Nuffel, N., Derudder, B., Witlox, F., 2010. Even important connections are not always meaningful: On the use of a polarisation measure in a typology of European cities in air transport networks. Tijdschrift voor Economische en Sociale Geografie 101, 333-348.

Vespermann, J., Wald, A., Gleich, R., 2008. Aviation growth in the Middle East - impacts on incumbent players and potential strategic reactions. Journal of Transport Geography 16, 388-394.

Vinciguerra S, Frenken, K., Valente, M., 2010. The geography of Internet infrastructure: An evolutionary simulation approach based on preferential attachment. Urban Studies 47, 1969-1984.

Warren, T.C., 2010. The geometry of security: Modeling interstate alliances as evolving networks. Journal of Peace Research 47, 697-709. 